\title{
Commentary: The Need for Bayesian Hypothesis Testing in Psychological Science
}

\author{
Jose D. Perezgonzalez * \\ Business School, Massey University, Palmerston North, New Zealand
}

Keywords: $p$-value, logic, reductio argument, modus tollens, data testing, statistics

\section{A commentary on}

\section{The Need for Bayesian Hypothesis Testing in Psychological Science}

by Wagenmakers, E. J., Verhagen, J., Ly, A., Matzke, D., Steingroever, H., Rouder, J. N., et al. (2017). Psychological Science Under Scrutiny: Recent Challenges and Proposed Solutions, eds S. O. Lilienfeld and I. D. Waldman (Chichester: John Wiley \& Sons), 123-138.

OPEN ACCESS

Edited by:

Ulrich Dettweiler,

University of Stavanger, Norway

Reviewed by:

Kathy Ellen Green,

University of Denver, United States

*Correspondence:

Jose D. Perezgonzalez

j.d.perezgonzalez@massey.ac.nz

Specialty section:

This article was submitted to

Educational Psychology,

a section of the journal

Frontiers in Psychology

Received: 09 June 2017 Accepted: 08 August 2017 Published: 23 August 2017

Citation:

Perezgonzalez JD (2017) Commentary: The Need for Bayesian Hypothesis Testing in Psychological Science. Front. Psychol. 8:1434. doi: 10.3389/fpsyg.2017.01434
Wagenmakers et al. (2017) argued the need for a Bayesian approach to inferential statistics in Psychological Science under Scrutiny. Their primary goal was to demonstrate the illogical nature of $p$-values, while, secondarily, they would also defend the philosophical consistency of the Bayesian alternative. In my opinion, they achieved their secondary goal but failed their primary one, thereby this contribution. I will, thus, comment on their interpretation of the logic underlying $p$-values without necessarily invalidating their Bayesian arguments.

Historical criticisms (e.g., Harshbarger, 1977, onwards) have already delved in the illogical nature of null hypothesis significance testing (NHST) - a mishmash of Fisher's, Neyman-Pearson's, and Bayes's ideas (e.g., Gigerenzer, 2004; Perezgonzalez, 2015a). Wagenmakers et al.'s original contribution is to generalize similar criticisms to the $p$-value itself, the statistic used by frequentists when testing research data.

Wagenmakers et al. assert that Fisher's disjunction upon obtaining a significant result-i.e., either a rare event occurred or $\mathrm{H}_{0}$ is not true (Fisher, 1959)-follows from a logically consistent modus tollens (also Sober, 2008): If $\mathrm{P}$, then $\mathrm{Q}$; not $\mathrm{Q}$; therefore not $\mathrm{P}$, which the authors parsed as, If $\mathrm{H}_{0}$, then not $\mathrm{y}$; $\mathrm{y}$; therefore not $\mathrm{H}_{0}$.

"Y" is defined as "the observed data... [summarized by] the $p$-value" (p. 126). Therefore, their first premise proposes that, if $\mathrm{H}_{0}$ is true, the observed $p$-values cannot occur (also Cohen, 1994; Beck-Bornholdt and Dubben, 1996). This seems incongruent, as the first premise of a correct modus tollens states a general rule- $\mathrm{H}_{0}$ implies "not $\mathrm{y}$ "-while the second premise states a specific test to such rule- "this y" has been observed. If the authors meant for " $y$ " to represent "significant data" as a general category in the first premise and as a specific realization in the second, a congruent modus tollens would ensue, as follows (also Pollard and Richardson, 1987):

If $\mathrm{H}_{0}$, then not $p<\operatorname{sig} ; p<\operatorname{sig}$ (observed); therefore not $\mathrm{H}_{0}$

Wagenmakers et al.'s (also Pollard and Richardson, 1987; Cohen, 1994; Falk, 1998) main argument is that a correct modus tollens is rendered inconsistent when made probabilistic, as follows:

If $\mathrm{H}_{0}$, then $p<$ sig very unlikely; $p<$ sig; therefore probably not $\mathrm{H}_{0}$ There are, however, three problems with (2), problems which I would like to comment upon. One problem is stylistic: The first premise states a redundant probability; that is, that a significant result-which already implies an unlikely or improbable event under $\mathrm{H}_{0}$-is unlikely. Therefore, the syllogism could be simplified as follows: 
If $\mathrm{H}_{0}$, then $p<$ sig; $p<$ sig; therefore probably not $\mathrm{H}_{0}$ Correction (3) now highlights another of the problems: The second premise simply affirms that an unlikely result just happened (also Cortina and Dunlap, 1997), something which is neither precluded by the first premise (no contrapositive ensues; Adams, 1988) nor formally conducive to a logical conclusion under modus tollens (Evans, 1982). Indeed, in the examples given (also by Cohen, 1994; Beck-Bornholdt and Dubben, 1996; Cortina and Dunlap, 1997; Krämer and Gigerenzer, 2005; Rouder et al., 2016), Tracy is a US congresswoman, Francis is the Pope, and John made money at the casino, each despite their odds against. Yet, none of those realizations deny the consequents. A correction, following Harshbarger (1977) and Falk (1998), would state:

If $\mathrm{H}_{0}$, then not $p<\operatorname{sig} ; p<$ sig; therefore probably not $\mathrm{H}_{0} \quad$ (4) Correction (4) brings to light the most important problem: Modus tollens is in the form, If $\mathrm{P}$, then Q; not Q; therefore not $\mathrm{P}$. Thus, whenever the consequent $(\mathrm{Q})$ gets denied in the second premise, it leads to denying the antecedent $(\mathrm{P})$ in the conclusion. Such operation ought to prevail with probabilistic premises, as well (e.g., Oaksford and Chater, 2001, 2009; Evans et al., 2015), whereby a probable consequent $\left(\mathrm{Q}_{p}\right)$ may be denied without its probability warranting transposition onto a nonprobabilistic antecedent $(\mathrm{P})$. For example, if all red cars $(\mathrm{P})$ have a $95 \%$ chance of getting stolen $(Q \geq 0.95)$ and we learn of a Lamborghini with a lesser probability of so disappearing (not $Q$ $\geq 0.95$ ), it is logical to conclude that the Lamborghini is not red (not P).

In comparison, Bayesian logic allows for the antecedent to be probable. For example, if John always submits to Nature (Q) whenever his subjective probability of getting published soars above $20 \%(P>0.2)$, yet he is not submitting his latest article (not $\mathrm{Q}$ ), it is logical to conclude that he probably expects no publication (not $P>0.2$ ).

\section{REFERENCES}

Adams, E. W. (1988). Modus tollens revisited. Analysis 48, 122-128. doi: 10.1093 /analys/48.3.122

Beck-Bornholdt, H. P., and Dubben, H. H. (1996). Is the Pope an alien? Nature 381:730. doi: $10.1038 / 381730$ d0

Cohen, J. (1994). The earth is round ( $\mathrm{p}<0.05)$. Am. Psychol. 49, 997-1003. doi: 10.1037/0003-066X.49.12.997

Cortina, J. M., and Dunlap, W. P. (1997). On the logic and purpose of significance testing. Psychol. Methods 2, 161-172. doi: 10.1037/1082-989X.2.2.161

Evans, J. St. B. T. (1982). The Psychology of Deductive Reasoning. London: Routledge \& Kegan Paul.

Evans, J. St. B. T., Thompson, V. A., and Over, D. E. (2015). Uncertain deduction and conditional reasoning. Front. Psychol. 6:398. doi: 10.3389/fpsyg.2015.00398

Falk, R. (1998). In criticism of the null hypothesis statistical test. Am. Psychol. 53, 798-799. doi: 10.1037/0003-066X.53.7.798

Fisher, R. A. (1959). Statistical Methods and Scientific Inference, 2nd Edn. Edinburgh: Oliver and Boyd.

Fisher, R. A. (1960). The Design of Experiments, 7th Edn. Edinburgh: Oliver and Boyd.

Gigerenzer, G. (2004). Mindless statistics. J. Soc. Econ. 33, 587-606. doi: 10.1016/j.socec.2004.09.033

Harshbarger, T. R. (1977). Introductory Statistics: A Decision Map, 2nd Edn. New York, NY: Macmillan.
We can, thus, envisage $\mathrm{P}$ or $\mathrm{Q}$, or both, as probable without either warranting inter-transposition of their probabilities, which brings us back to a valid modus tollens (1). Said otherwise, while Bayesian statistics allow for the antecedent to be probable $\left(\mathrm{P}_{\mathrm{p}}\right)$, Fisher's and Neyman-Pearson's tests assume exact antecedents (P); therefore, a probabilistic conclusion does not hold with frequentist tests (Mayo, 2017).

It ought to be noted that the $p$-value is a statistic descriptive of the probability of the data under $\mathrm{H}_{0}\left[\mathrm{p}\left(\mathrm{D} \mid \mathrm{H}_{0}\right)\right]$ (Perezgonzalez, 2015b). The reductio ad absurdum argument may be informed by, but it is not dependent on, such $p$ value, the reductio being determined exclusively by the chosen level of significance. For "it is open to the experimenter to be more or less exacting in respect of the smallness of the probability he would require before he would be willing to admit that his observations have demonstrated a positive result. It is obvious that an experiment would be useless of which no possible result would satisfy him" (Fisher, 1960, p.13).

In conclusion, the technology of frequentist testing holds their modus tollens logically. Wagenmakers et al.'s criticism of the $p$-value is faulty in that they allow for a probability transposition not warranted either by modus tollens or by the technical apparatus of Fisher's and of Neyman-Pearson's tests. This critique, however, does not extend to their Bayesian argumentation, an approach much needed for testing hypotheses-rather than just testing data-in contemporary science.

\section{AUTHOR CONTRIBUTIONS}

The author confirms being the sole contributor of this work and approved it for publication.

Krämer, W., and Gigerenzer, G. (2005). How to confuse with statistics or: the use of misuse of conditional probabilities. Stat. Sci. 20, 223-230. doi: 10.1214/088342305000000296

Mayo, D. G. (2017). If You're Seeing Limb-Sawing in p-value Logic, You're Sawing off the Limbs of Reductio Arguments [Web Log Post]. Available online at: https://errorstatistics.com/2017/04/15/if-youre-seeing-limb-sawingin-p-value-logic-youre-sawing-off-the-limbs-of-reductio-arguments/

Oaksford, M., and Chater, N. (2001). The probabilistic approach to human reasoning. Trends Cogn. Sci. 5, 349-357. doi: 10.1016/S1364-6613(00) 01699-5

Oaksford, M., and Chater, N. (2009). Précis of bayesian rationality: the probabilistic approach to human reasoning. Behav. Brain Sci. 32, 69-84. doi: 10.1017/S0140525X09000284

Perezgonzalez, J. D. (2015a). Fisher, Neyman-Pearson or NHST? A tutorial for teaching data testing. Front. Psychol. 6:223. doi: 10.3389/fpsyg.2015. 00223

Perezgonzalez, J. D. (2015b). P-values as percentiles. Commentary on: "Null hypothesis significance tests. A mix-up of two different theories: the basis for widespread confusion and numerous misinterpretations." Front. Psychol. 6:341. doi: 10.3389/fpsyg.2015. 00341

Pollard, P., and Richardson, J. T. E. (1987). On the probability of making type I errors. Psychol. Bull. 102, 159-163. doi: 10.1037/0033-2909. 102.1 .159 
Rouder, J. N., Morey, R. D., Verhagen, J., Province, J. M., and Wagenmakers, E. J. (2016). Is there a free lunch in inference? Top. Cogn. Sci. 8, 520-547. doi: $10.1111 /$ tops.12214

Sober, E. (2008). Evidence and Evolution. The Logic Behind the Science. Cambridge: Cambridge University Press.

Wagenmakers, E. J., , Verhagen, J., Ly, A., Matzke, D., Steingroever, H., Rouder, J. N., et al. (2017). "The need for Bayesian hypothesis testing in psychological science," in Psychological Science Under Scrutiny: Recent Challenges and Proposed Solutions, eds S. O. Lilienfeld and I. D. Waldman (Chichester: John Wiley \& Sons), 123-138.
Conflict of Interest Statement: The author declares that the research was conducted in the absence of any commercial or financial relationships that could be construed as a potential conflict of interest.

Copyright $\odot 2017$ Perezgonzalez. This is an open-access article distributed under the terms of the Creative Commons Attribution License (CC BY). The use, distribution or reproduction in other forums is permitted, provided the original author(s) or licensor are credited and that the original publication in this journal is cited, in accordance with accepted academic practice. No use, distribution or reproduction is permitted which does not comply with these terms. 